\title{
CIELab Color Moments: Alternative Descriptors for LANDSAT Images Classification System
}

\author{
Momen Warna CIELab: Deskriptor Alternatif untuk Sistem Klasifikasi \\ Citra LANDSAT
}

\author{
Retno Kusumaningrum ${ }^{1}$, Hisar Maruli Manurung ${ }^{2}$, Aniati Murni Arymurthy ${ }^{2}$ \\ ${ }^{1}$ Department of Informatics, Universitas Diponegoro, Jl. Prof. Soedarto, SH, Tembalang, Semarang, 50275 \\ ${ }^{2}$ Faculty of Computer Science, Universitas Indonesia, Kampus UI Depok 16424 \\ Email: retno_ilkom@undip.ac.id, maruli@cs.ui.ac.id, aniati@cs.ui.ac.id
}

\begin{abstract}
This study compares the image classification system based on normalized difference vegetation index (NDVI) and Latent Dirichlet Allocation (LDA) using CIELab color moments as image descriptors. It was implemented for LANDSAT images classification by evaluating the accuracy values of classification systems. The aim of this study is to evaluate whether the CIELab color moments can be used as an alternatif descriptor replacing NDVI when it is implemented using LDA-based classification model. The result shows that the LDA-based image classification system using CIELab color moments provides better performance accuracy than the NDVI-based image classification system, i.e $87.43 \%$ and $86.25 \%$ for LDA-based and NDVI-based respectively. Therefore, we conclude that the CIELab color moments which are implemented under the LDA-based image classification system can be assigned as alternative image descriptors for the remote sensing image classification systems with the limited data availability, especially when the data only available in true color composite images.
\end{abstract}

Keywords: Normalized Difference Vegetation Index, CIELab, color moments, Latent Dirichlet Allocation, LANDSAT, remote sensing image classification

\begin{abstract}
Abstrak
Penelitian ini membandingkan 2 jenis sistem klasifikasi citra, yaitu sistem berbasis Normalized Difference Vegetation Index (NDVI) serta sistem berbasis Latent Dirichlet Allocation (LDA) menggunakan momen warna CIELab sebagai deskriptornya. Penelitian tersebut diimplementasikan untuk klasifikasi citra LANDSAT dengan mengevaluasi nilai akurasi dari kedua jenis sistem tersebut. Tujuan dari studi ini adalah untuk mengevaluasi apakah momen warna CIELab dapat digunakan sebagai deskriptor alternatif dari NDVI ketika diterapkan menggunakan model klasifikasi berbasis LDA. Hasil eksperimen menunjukkan bahwa sistem klasifikasi berbasis LDA menggunakan momen warna CIELab memberikan kinerja akurasi yang lebih baik dibandingkan sistem klasifikasi berbasis NDVI, dengan perbandingan nilai akurasi sebesar 87,43\% untuk model klasifikasi berbasis LDA dan 86,25\% untuk model klasifikasi berbasis NDVI. Oleh karena itu, dapat disimpulkan bahwa momen warna CIELab yang diimplementasikan pada sistem klasifikasi berbasis LDA dapat digunakan sebagai alternatif deskriptor untuk sistem klasifikasi citra penginderaan jauh pada saat data yang tersedia terbatas, khususnya ketika hanya citra true color composite yang tersedia.
\end{abstract}

Kata kunci: Normalized Difference Vegetation Index, CIELab, momen warna, Latent Dirichlet Allocation, LANDSAT, klasifikasi citra penginderaan jauh

\section{Introduction}

The success value of image classification process is influenced by the suitability of the used features and the domain of images to be classified. In remote sensing images, spectral values are widely used for remote sensing images

Received: 15 Feb 2015; Revised: 20 Feb 2015; Accepted: 1 April 2015 ; Published online: 30 April 2015

(C)2014 INKOM 2014/14-NO409 classification systems [1], [2], [3], [4], [5], [6], [7]. This is because the spectral values of different materials reflect and absorb differently at different wave lengths. Thus, the objects on the earth surfaces can be easily differentiated by their spectral reflectance signatures.

Vegetation can be easily distinguished from other types of land cover by the high NIR (near infrared) but generally low visible reflectance. One of discriminative features for distinguishing 
between vegetation area and non-vegetation area is NDVI (normalized difference vegetation index) which employs near infrared band and red (visible) band [2], [6], [8], [9].

However, the NDVI value can only be extracted when we have multispectral images; in particular, the availability of false color composite images. There are some types of these composite images. A common false color composite image for displaying a LANDSAT multispectral image is as follows:

- $\mathrm{R}=$ Band 4 (NIR Band)

- $\mathrm{G}=$ Band 3 (Red Band)

- $\mathrm{B}=$ Band 2 (Green Band)

Therefore, we propose the use of CIELab color space as an alternative feature of NDVI due to the limitation of data availability. In this study, we compare the accuracy value of an image classification system which employs CIELab color space in LDA-based image classification system and NDVI-based image classification system. The selection of LDA as a classification model since this model provides good performance for classifying land cover in another remote sensing image, IKONOS, compared to the other traditional classification models such as C4.5 and Naïve Bayes tree [10]. These systems are implemented for LANDSAT images.

This paper is organized as follows. In section 2, we will review the LDA-based classification model. Section 3 outlines the NDVI and CIELab color space. The experimental scenario and results is described in section 4. The conclusion of entire study will be explained in section 5 .

\section{LDA Based Classification Model}

This section reviews LDA in general and then describes its implementation for image classification model.

\subsection{LDA in General}

LDA is a probabilistic latent space model in which each document is represented as a random mixture over a set of latent topics and each topic is represented as a distribution over a predefined and fixed vocabulary [11]. LDA can be seen in two ways, i.e. generative process and inference process. In this study, we implement LDA as inference process since we use this model for image classification process. It means that we implement LDA as inverse process of generative model, i.e. we learn a set of words in the corpus in order to identify the word distribution for each topic $(\varphi)$ and topic proportion for each document $(\theta)$. A corpus consists of $D$ documents where each document consists of $N$ words. In order to overcome the existence of complex coupling latent variables which leads the LDA inference into an intractable process, we can implement the inference process using approximate posterior inference algorithms such as mean field variational methods [11], Gibbs sampling [12], and collapsed variational inference [13].

In this study, we implement Gibbs sampling algorithm. This algorithm updates each of the variables respectively based on the conditional probability of all other variables, although the joint probability distribution is unknown. The goal of the inference process is to compute the probability of topic $z$ given word $w$ for the entire data collection.

$$
p(\vec{z} \mid \vec{w})=\frac{\prod_{i=1}^{W} p\left(w_{i}, z_{i}\right)}{\prod_{i=1}^{W} \sum_{k=1}^{K} p\left(z_{i}=k, w_{i}\right)}
$$

Gibb sampling algorithm is used to compute the probability of topic $z_{i}$ being assigned to word token $w_{i}$ given all other topic assignments to all other words, full conditional probability $p\left(z_{i}=k \mid \vec{z}_{\neg i}, \vec{w}\right)$. This probability is used to simulate $p(\vec{z} \mid \vec{w})$.

$$
\begin{aligned}
& p\left(z_{i}=k \mid \vec{z}_{\neg i}, \vec{w}, \vec{\alpha}, \vec{\beta}\right)=\frac{p(\vec{z}, \vec{w} \mid \vec{\alpha}, \vec{\beta})}{p\left(\vec{z}_{\neg i}, \vec{w}_{\neg i} \mid \vec{\alpha}, \vec{\beta}\right)} \\
& =\frac{n_{k, \neg i}^{(t)}+\beta_{t}}{\sum_{t=1}^{V} n_{k, \neg i}^{(t)}+\beta_{t}} \cdot \frac{n_{d, \neg i}^{(k)}+\alpha_{k}}{\left[\sum_{k=1}^{K} n_{d}^{(k)}+\alpha_{k}\right]-1}
\end{aligned}
$$

By the definition, we can compute the value of $\varphi_{k}$ and $\theta_{d}$ as follows

$$
\begin{gathered}
\varphi_{k}=p(w=t \mid z=k)=\frac{n_{t, k}+\beta_{t}}{\sum_{t=1}^{V} n_{k, t}+\beta_{t}} \\
\theta_{d}=p(z=k \mid d)=\frac{n_{d, k}+\alpha_{k}}{\sum_{k=1}^{K} n_{d, k}+\alpha_{k}}
\end{gathered}
$$

Where $n_{t, k}$ is the number of words $w$ equals to $t$ that are assigned as topic $z$ equals to $k$, and $n_{d, k}$ is the number of words in document $d$ that are assigned as topic $z$ equals to $k$. 


\subsection{LDA for Image Classification}

As mentioned before, we implement LDA as inference process for image classification. There are two main processes in LDA-based image classification, i.e. training process and testing process. The aim of training process is to get the estimator for classification process, while the testing process is to classify and segment an image into vegetation and non vegetation area. Training process consists of five steps, i.e.:

\subsubsection{Building the training data}

Since the final purpose of our task is to classify an image into vegetation and non vegetation area, then we build the training data which consist of 2 set of images. The first set is sample of vegetation images and the second set is sample of non vegetation images. Each set consists of 30 images in the form of $16 \times 16$ pixels image patch. These image patches are subsequently called as visual document.

\subsubsection{Extracting visual features}

In this study, we employ two image features including NDVI and CIELab color moments. These features were extracted over $4 \times 4$ pixels image patch which is called as visual words. The detail explanation of those features can be seen in the next section.

\subsubsection{Generating visual vocabulary}

The visual vocabulary is built using Gaussian mixture clustering from Bouman [14] and integrated visual vocabulary (IVV) as an approach. This approach is built as the union of all centroids obtained from the separate quantization process of each class.

\subsubsection{Representing each visual document as Bag of Visual Words (BoVW)}

Based on the visual vocabulary from previous step, we use K-nearest neighbor to represent each visual document as BoVW.

\subsubsection{Learning data using LDA model}

LDA learns the training data, a set of visual words, and the given input of hyperparameters $\alpha=50 / \mathrm{K}$ and $\beta=0.01$, number of topics $K$, and number of iterations $T$, in order to get the words distribution for each topic and topic proportions for each document. Subsequently, the topic proportion for each class can be computed as a harmonic mean of topic proportion for each document of all visual documents in the respective class.
In testing process, the same steps as training process are applied including the feature extraction and BoVW representation process. The visual documents were generated using overlapping layout. Based on BoVW for each visual document, we can calculate the value of topic proportion for each visual document. The final task is to use Kullback-Leibler Divergence (KLD) [15] for comparing similarity of distribution between topic proportion each visual document in testing data and the estimator value, that is, topic proportion of each class from training data. The smallest value of KLD shows the most similar distribution. Majority vote was used to fuse the final classification results for each pixel which were obtained for each visual document class.

\section{NDVI and CIELab Color Moments}

As mentioned before, this study proposes the used of CIELab color moment as an alternative feature of NDVI for distinguishing vegetation and non vegetation area. The following sub section explains the NDVI and CIELab color moment in brief.

\subsection{NDVI}

NDVI was derived using formula as follows:

$$
N D V I=\frac{R_{N I R}-R_{R E D}}{R_{N I R}+R_{R E D}}
$$

Where $R_{N I R}$ is reflectance in the near infrared band and $R_{R E D}$ is reflectance in the red band. In theory, NDVI value has range between -1.0 and +1.0. Non vegetation areas such as clouds, barren, water, snow and ice give negative NDVI values, whereas positive values of NDVI indicate vegetated area [16].

\subsection{NDVI}

CIELab is a color space developed by CIE (Commission Internationale de L'Eclairage). This color space is linear to the visual perception and close to human vision [17]. CIELab consists of 3 color coordinates, i.e.:

- $L^{*}$ coordinates

It represents the lightness which shows grey level when $a^{*}=0$ and $b^{*}=0$. This coordinate has scale from 0 to 100 , where 0 represents black and 100 represents white.

- $a^{*}$ coordinates

This coordinate represents the red/green sensation and has scale from -127 to +127 , where - 
127 represents pure green and +127 represents pure red

\section{- $b^{*}$ coordinates}

It represents yellow/blue sensation and also has the scale from -127 to +127 , where -127 means pure blue and +127 means pure yellow.

The conversion of this color space requires intermediate conversion, that is, the conversion process of RGB image into XYZ color space. Based on the XYZ color space, the next step is to convert the XYZ color space into CIELab color space. Formally, it can be defined as follows:

$$
\begin{gathered}
L^{*}= \begin{cases}116\left(\frac{Y}{Y_{n}}\right)^{1 / 3}-16, & \text { if } t>0.008856 \\
903.3\left(\frac{Y}{Y_{n}}\right), & \text { if } t \leq 0.008856\end{cases} \\
a^{*}=500\left(f\left(\frac{X}{X_{n}}\right)-f\left(\frac{Y}{Y_{n}}\right)\right) \\
b^{*}=200\left(f\left(\frac{Y}{Y_{n}}\right)-f\left(\frac{Z}{Z_{n}}\right)\right)
\end{gathered}
$$

Where $X, Y, Z$ are pixel values of each channel in $\mathrm{XYZ}$ color space. And the other variables are as follows:

$$
\begin{gathered}
f(t)= \begin{cases}t^{1 / 3}, & \text { if } t>0.008856 \\
7.787 * t+\frac{4}{29}, & \text { if } t \leq 0.008856\end{cases} \\
{\left[\begin{array}{c}
X_{n} \\
Y_{n} \\
Z_{n}
\end{array}\right]=\left[\begin{array}{c}
0.950456 \\
1 \\
1.088754
\end{array}\right]}
\end{gathered}
$$

In this study, we use color moments as image descriptors including mean, standard deviation, and skewness [18]. While the illustration of CIELab color space is described as follow.

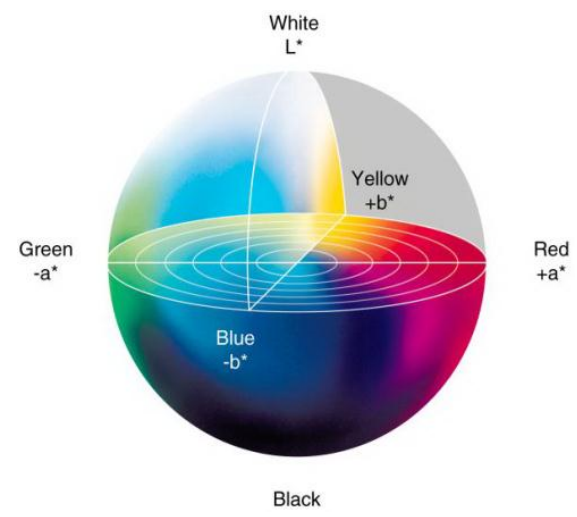

Fig. 1. CIELab Color Space

\section{Experiments and Results}

\subsection{Experimental Setup and Scenario}

Multispectral LANDSAT images were used as domain image for image classification. The training data consists of 60 images, including 30 images of vegetation and 30 images of nonvegetation, whereas the testing data consists of an image of $256 \times 256$ pixels. The following fig. 2 show the sample of original image.
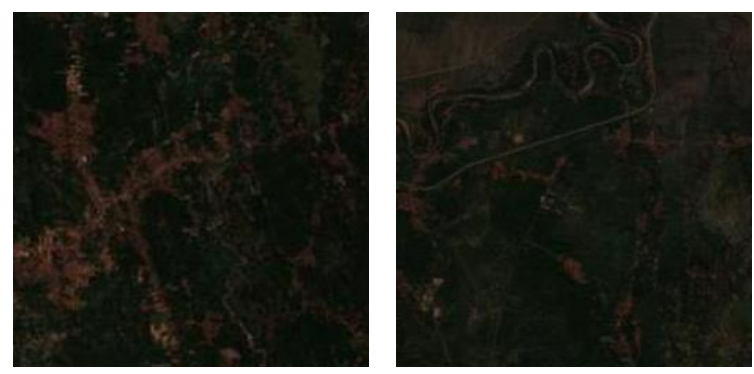

Fig. 2. Original Image and Its Ground Truth Classified Image

The experiment was implemented using Matlab R2010a under Windows $7-64$ bit and the hardware specifications are as follows:

- Intel Core i5-520M $2.40 \mathrm{GHz}$

- 8 GB of memory (RAM)

- 500GB of hard disk drive

The main task of this study is to compare the accuracy value of LDA-based image classification system using CIELab color moments and NDVIbased image classification system.

\subsection{Results and Analysis}

The best result of LDA-based image classification system using CIELab color space is obtained for the following variable values, i.e. 5 for the number of topics and and 50 for the number of iterations. Figure 3 shows the samples of classified image under the previous setup. Whereas the result of NDVI-based image classification system for the same image is described in fig. 4.
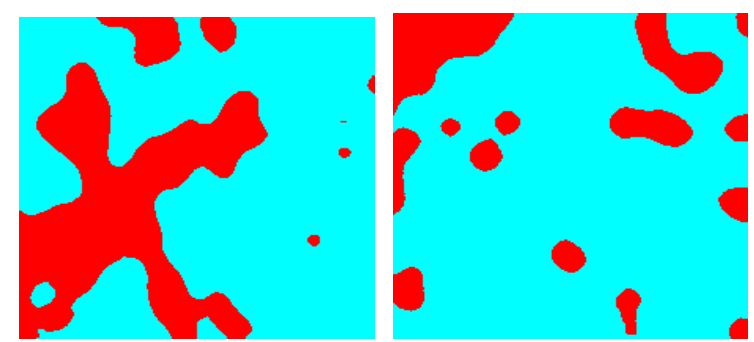

Fig. 3. Result of LDA-based image classification system using CIELab color moments 

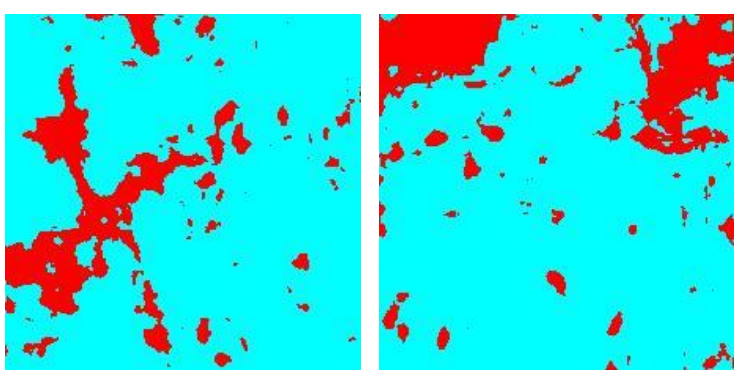

Fig. 4. Result of NDVI-based image classification

Evaluation processes were performed by computing accuracy values for both LDA-based and NDVI-based classification system as shown in table 1 . The accuracy values were computed based on ratio between the number of correct classified pixels (pixel with the same label between classified image and ground truth image) and the number of pixels in an image, while overall accuracy value was computed as an average of all testing images accuracy values.

Table 1. Experimental results

\begin{tabular}{ccc}
\hline & \multicolumn{2}{c}{$\begin{array}{c}\text { Overall Accuracy of Image } \\
\text { Classification Systems }\end{array}$} \\
\cline { 2 - 3 } No & $\begin{array}{c}\text { LDA-based and } \\
\text { CIELab Color } \\
\text { Moments }\end{array}$ & NDVI-based \\
\hline \multirow{2}{*}{1} & $87.43 \%$ & $86.25 \%$ \\
\hline
\end{tabular}

Table 1 shows that the LDA-based using CIELab Color Moments gives better result than NDVIbased image classification system. This condition is influenced by the characteristics of CIELab color space which linear to the visual perception and close to human vision.

\section{Conclusion}

In this study, we proposed the used of CIELab color moment which is implemented under the LDA-based classification system for LANDSAT images as an alternative image descriptor to overcome the limitation of data availability when data only available in true color composite image. The classification systems are implemented to determine the vegetation and non vegetation area. The results show that the used of CIELab color space under the LDA-based image classification system outperforms the traditional NDVI-based classification system by about $1.18 \%$.

\section{References}

[1] J. Li, "Hierarchical Land Cover Information Retrieval in Object-Oriented Remote Sensing Image Databases with Native Queries," in Proceedings of the 45th Annual Southeast Regional Conference, 2007, pp. 467-472.

[2] N. Durand, G. Forestier, P. Ganc, O. Boussa, and A. Puissant, "Ontology-based Object Recognition for Remote Sensing Image Interpretation," in Proceedings of the 19th IEEE International Conference on Tools with Artificial Intelligence, 2007, pp. 472-479.

[3] C. Li, L. Khan, B. Thuraisingham, M. Husain, S. Chen, and F. Qiu, "Geospatial data mining for national security: Land cover classification and semantic grouping," in Proceedings of IEEE Conference on Intelligence and Security Informatics 2007, 2007, pp. 254-261.

[4] T. Liu, K. Muramatsu, D. Motomasa, P. Li, and L. Zhang, "Region-based Image Retrieval Using Semantic Mining," Doshisha Univ. world wide Bus. Rev., vol. 10, no. 2, pp. 97-104, 2009.

[5] N. Ruan, N. Huang, and W. Hong, "Semanticbased image retrieval in remote sensing archive: An ontology approach," in IEEE Geoscience and Remote Sensing Symposium, 2006, pp. 2903-2906.

[6] T. Liu, L. Zhang, P. Li, and H. Lin, "Remotely sensed image retrieval based on region-level semantic mining," EURASIP J. Image Video Process., vol. 2012, no. 1, p. 4, 2012.

[7] W. Yi, H. Tang, and Y. Chen, "An ObjectOriented Semantic Clustering Algorithm for HighResolution Remote Sensing Images Using the Aspect Model," IEEE Geosci. Remote Sens. Lett., vol. 8, no. 3, pp. 522-526, 2011.

[8] K. C. Tan, H. S. Lim, M. Z. MatJafri, and K. Abdullah, "Landsat data to evaluate urban expansion and determine land use/land cover changes in Penang Island, Malaysia," Environ. Earth Sci., vol. 60, no. 7, pp. 1509-1521, Sep. 2009.

[9] A. Ghorbani, A. M. Mossivand, and A. E. Ouri, "Utility of the Normalised Difference Vegetation Index ( NDVI ) for land / canopy cover mapping in Khalkhal County ( Iran )," Ann. Biol. Res., vol. 3, no. 12, pp. 5494-5503, 2012.

[10] R. Kusumaningrum, H. Wei, R. Manurung, and A. Murni, "Integrated visual vocabulary in latent Dirichlet allocation-based scene classification for IKONOS image," J. Appl. Remote Sens., vol. 8, no. 1, pp. 083690-1 s/d 083690-18, Jan. 2014.

[11] D. M. Blei, A. Y. Ng, and M. I. Jordan, "Latent Dirichlet Allocation," J. Mach. Learn. Res., vol. 3, pp. 993-1022, 2003.

[12] T. L. Griffiths and M. Steyvers, "A probabilistic approach to semantic representation," in Proc. 24th Annual Conference of the Cognitive Science Society, 2002, pp. 381-386.

[13] Y. W. Teh, D. Newman, and M. Welling, "A Collapsed Variational Bayesian Inference 
Algorithm for Latent Dirichlet Allocation," in Proc. 20th Annual Conference on Neural Information Processing Systems, 2006, pp. 13531360.

[14] C. A. Bouman, "CLUSTER: An Unsupervised Algorithm for Modeling Gaussian Mixtures Developed by:," 2005. [Online]. Available: https://engineering.purdue.edu/ bouman/software/ cluster/manual.pdf. [Accessed: 22-Feb-2012].

[15] G. Heinrich, "Parameter estimation for text analysis," 2009.
[16] F. Yuan and M. E. Bauer, "Comparison of impervious surface area and normalized difference vegetation index as indicators of surface urban heat island effects in Landsat imagery," Remote Sens. Environ., vol. 106, no. 3, pp. 375-386, Feb. 2007.

[17] A. Ford and A. Roberts, "Colour Space Conversions," 1998. [Online]. Available: http://www.poynton.com/PDFs/coloureq.pdf. [Accessed: 22-Jun-2011].

[18] M. Stricker and M. Orengo, "Similarity of Color Images," in Proc. SPIE 2420, Storage and Retrieval for Image and Video Databases III, 1995, pp. 381-392. 